\title{
Modified Ross Procedure for a Young Woman with a Root Abscess on a Bicuspid Aortic Valve: Report of a Case
}

\author{
Yusuke Misumi, Tomoyuki Fujita*, Yusuke Shimahara, Hiroki Hata, Soichiro Kitamura, \\ Junjiro Kobayashi \\ Department of Cardiovascular Surgery, National Cerebral and Cardiovascular Center, Osaka, Japan \\ Email: ${ }^{\text {tomofujita@nifty.com }}$
}

Received 19 July 2015; accepted 14 August 2015; published 17 August 2015

Copyright (C) 2015 by authors and Scientific Research Publishing Inc.

This work is licensed under the Creative Commons Attribution International License (CC BY).

http://creativecommons.org/licenses/by/4.0/

(c) (i) Open Access

\section{Abstract}

A 19-year-old woman with a bicuspid aortic valve was admitted because of active infective endocarditis with a root abscess. Four weeks of antibiotic therapy achieved negative blood cultures and normalized inflammatory signs; however, echocardiography revealed severe aortic regurgitation through an abscess cavity located at the root. The modified Ross procedure, in which the pulmonary autograft was reinforced with a prosthetic graft to prevent postoperative annular dilation, was successfully performed. The postoperative clinical course was uneventful, and echocardiography performed at 1 year showed trivial aortic regurgitation. Selection of homograft may benefit young woman who wishes to bear children, and covering pulmonary autograft by a prosthetic graft in order to prevent annular dilatation of autograft in patient with bicuspid aortic valve, may be allowed only under negative infection sign.

\section{Keywords}

Ross Procedure, Endocarditis, Homograft, Bicuspid Aortic Valve

\section{Introduction}

The Ross procedure is a treatment of choice for aortic valve endocarditis owing to its durability with an excellent reinfection-free rate as high as 95\% [1]. Good durability of the pulmonary valve homograft is also reported for the Ross procedure for infectious endocarditis [2]. Because the Ross procedure does not require long-term anticoagulation and poses a significantly lower risk of thromboembolism than prosthetic valves, the Ross pro-

"Corresponding author.

How to cite this paper: Misumi, Y., Fujita, T., Shimahara, Y., Hata, H., Kitamura, S. and Kobayashi, J. (2015) Modified Ross Procedure for a Young Woman with a Root Abscess on a Bicuspid Aortic Valve: Report of a Case. World Journal of Cardiovascular Diseases, 5, 199-202. http://dx.doi.org/10.4236/wjcd.2015.58022 
cedure is preferred in young patients, especially in women of child-bearing age [3]-[5]. However, autograft dilatation after the Ross procedure is a major late complication. Individuals with bicuspid aortic valves with or without a dilated annulus are considered to be at high risk of postoperative aortic root dilatation and neo-aortic insufficiency [1] [6]. Some of the modifications of the Ross procedure showed good mid-term results, although these modifications have not been applied in patients with aortic valve endocarditis [1] [7]. The modified Ross procedure that utilizes a prosthetic graft might have been avoided because of concerns about prosthesis infection. Here, we report a case of a young woman with a bicuspid aortic valve, severe aortic regurgitation and a root abscess due to infectious endocarditis, who successfully underwent the modified Ross procedure, in which the autograft was completely encased in a prosthetic graft prior to implantation.

\section{Case Report}

A 19-year-old woman with a bicuspid aortic valve was referred to our hospital because of infective endocarditis. She presented with a fever of $38^{\circ} \mathrm{C}$ and had a positive blood culture for Streptococcus viridans. Transthoracic echocardiography revealed that the aortic valve was bicuspid and both leaflets were thickened. A 4-week course of antibiotic therapy with ceftriaxone was immediately initiated and symptoms improved. After therapy, laboratory data showed that C-reactive protein and white blood cell counts were within normal limits. However, echocardiography showed severe aortic regurgitation through a cavity located at the aortic annulus. Left ventricular end-diastolic and end-systolic dimensions were $53 \mathrm{~mm}$ and $34 \mathrm{~mm}$, respectively, with an ejection fraction of $65 \%$. The mean pressure gradient and peak velocity across the aortic valve was $22 \mathrm{mmHg}$ and $3 \mathrm{~m} / \mathrm{s}$, respectively. Transesophageal echocardiography showed a $17 \times 8 \mathrm{~mm}$-sized cavity at the aortic root, which was a perforation of the sinus of Valsalva into the left ventricle (Figure 1(A) and Figure 1(B)). Enhanced computed tomography showed that the dimensions of the aortic valve, sinus of Valsalva, and ascending aorta were $23 \mathrm{~mm}$, $31 \mathrm{~mm}$, and $27 \mathrm{~mm}$, respectively (Figure 2).

After discussion with the patient, she consented to a modified Ross procedure using a prosthetic graft for reinforcement to prevent dilatation of the autograft. Intraoperatively, the abscess cavity was carefully debrided,

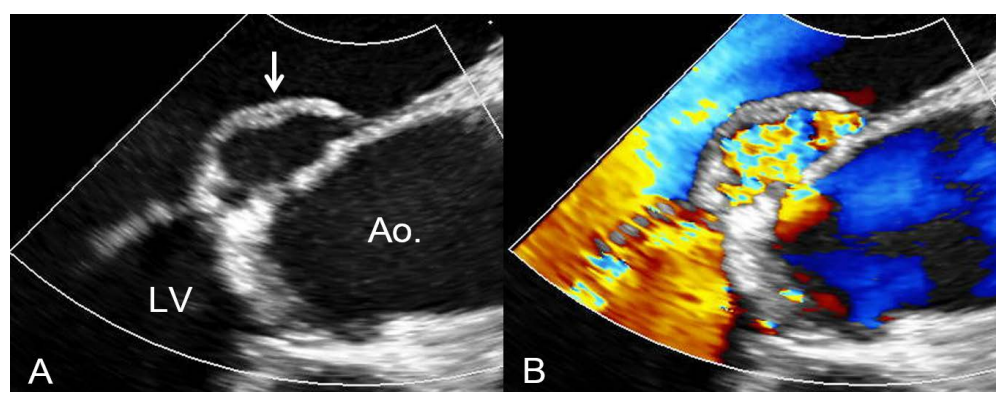

Figure 1. Preoperative transesophageal echocardiography. White arrow indicates an abnormal cavity at the aortic annulus (A). The cavity was connected the left ventricle to the ascending aorta (B). Ao, ascending aorta; $\mathrm{LV}$, left ventricle.

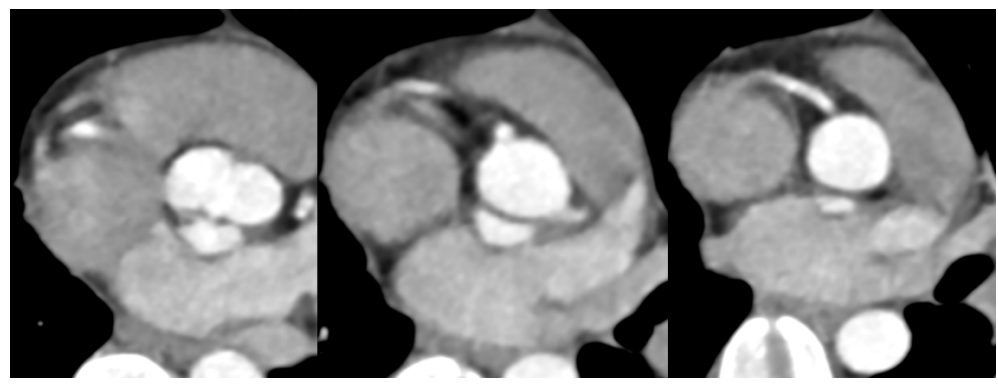

Figure 2. Preoperative enhanced computed tomography revealed an enhanced cavity located at the aortic annulus in the non coronary sinus and the dimensions of the aortic valve, sinus of Valsalva, and ascending aorta were $23 \mathrm{~mm}, 31 \mathrm{~mm}$, and $27 \mathrm{~mm}$, respectively. 
coronary buttons were created and the sinus of Valsalva was excluded. The pulmonary autograft was harvested from the right ventricular outflow tract with a short muscular rim. Excess fat on the outer surface was trimmed. The dimensions of the aortic and pulmonary annuli were $19 \mathrm{~mm}$ and $21 \mathrm{~mm}$, respectively. Therefore, a $24 \mathrm{~mm}$ polyester vascular prosthesis (Gelweave ${ }^{\mathrm{TM}}$ woven polyester graft; Vascutek, Terumo Cardiovascular Systems Inc., Ann Arbor, MI) was selected. The autograft was placed inside the prosthetic graft, and three individual stitches were placed to fix each commissure to the proximal graft (Figure 3). Continuous over and over sutures of 4-0 Prolene (Ethicon Inc., Somerville, NJ) were used to attach the proximal and distal ends of the autograft and the prosthetic graft, after adjusting the length by cutting prosthetic graft. The reinforced autograft construct was placed into the aortic annulus and secured with 4-0 Prolene continuous sutures.

At locations that were best aligned with the left and right coronary arteries, small windows were made in the prosthetic graft and corresponding button holes were created in the wall of the autograft with a $4.5 \mathrm{~mm}$ aortic puncher. Both coronary buttons were reimplanted into both the prosthesis and the autograft using the Carrel patch technique with 6-0 Prolene continuous sutures. Distal anastomosis to the ascending aorta was subsequently performed with 4-0 Prolene continuous sutures. Finally, the right ventricle outflow tract was reconstructed with a pulmonary homograft. Intraoperative transesophageal echocardiography revealed trivial central aortic regurgitation and no pulmonary regurgitation. The cardiopulmonary bypass and aortic cross-clamping times were 186 minutes and 133 minutes, respectively. The postoperative course was uneventful and she was discharged home on the $10^{\text {th }}$ postoperative day with warfarin and diuretics. Warfarin was discontinued at 3 months after surgery and no cardiac infarction or heart failure symptoms have been observed at follow-up. Transthoracic echocardiography performed at 1 year showed only trivial aortic regurgitation without annular dilatation (Figure 4).

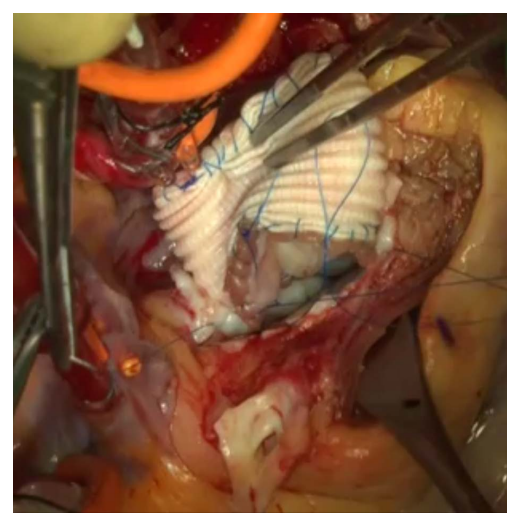

Figure 3. The autograft was placed inside the prosthetic graft and both the proximal and distal ends were fixed with a running suture of 4-0 Prolene. This figure shows that the reinforced autograft construct was connected to the aortic annulus with a running suture of 4-0 Prolene to complete root replacement.

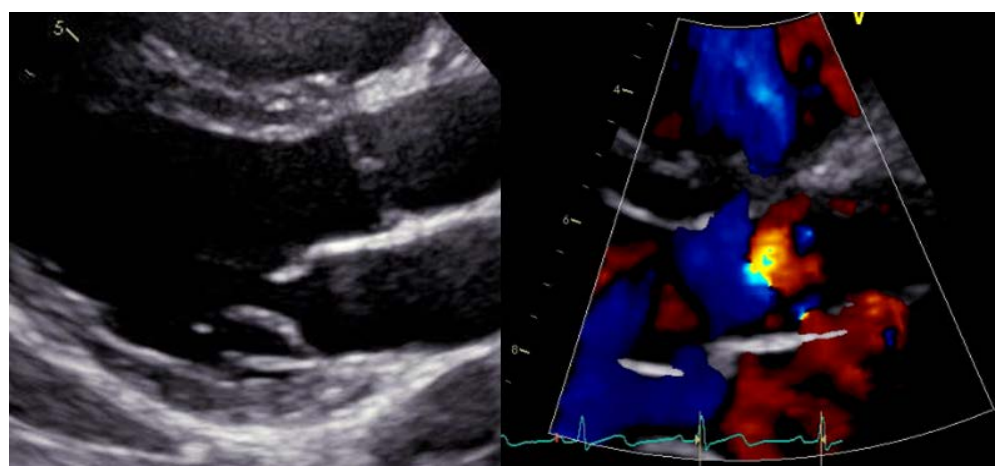

Figure 4. Transthoracic echocardiography performed at 1 year showed only trivial aortic regurgitation without annular dilatation. 


\section{Discussion}

Progressive dilatation of the neo-aortic root with subsequent autograft insufficiency after the Ross procedure is sometimes observed, especially among patients with a bicuspid aortic valve due to bicuspid aortic valve-associated aortopathy [6] [7]. The modified Ross procedure reportedly prevented the increase in size of the entire neo-aortic root at mid-term follow-up [6].

There is controversy regarding the use of a prosthesis in patients with endocarditis. The application of a prosthetic graft outside of the pulmonary homograft can violate the surgical principles of endocarditis and should not be advocated in this setting. However, because the Dacron prosthesis only covered the outside of the pulmonary homograft, a hematogenous infection is unlikely to result in infection of the prosthesis. As long as sufficient preoperative antibiotic therapy achieved clearance of the infectious endocarditis and debridement of the root is completed, the modified Ross procedure is considered to be a good option to cure a root abscess, especially for young women who wish to become pregnant in the future.

\section{Conclusion}

We have experienced a successful case of young woman who underwent modified Ross procedure to treat a healed root abscess on a bicuspid aortic valve. Selection of homograft may benefit young woman who wishes to bear children. However, although implanting pulmonary autograft into a prosthetic graft may be useful to prevent annular dilatation of autograft in patient with bicuspid aortic valve, this procedure may be allowed only when the root is free from active infection.

\section{Disclosure Statement}

Y. Misumi and other co-authors have no conflict of interest.

\section{References}

[1] Elkins, R.C., Thompson, D.M., Lane, M.M., Elkins, C.C. and Peyton, M.D. (2008) Ross Operation: 16-Year Experience. Journal of Thoracic and Cardiovascular Surgery, 136, 623-630. http://dx.doi.org/10.1016/j.jtcvs.2008.02.080

[2] Kitamura, S., Yagihara, T., Kobayashi, J., Nakajima, H., Toda, K., Fujita, T., Ichikawa, H., Ogino, H., Nakatani, T. and Taniguchi, S. (2011) Mid- to Long-Term Outcomes of Cardiovascular Tissue Replacements Utilizing Homografts Harvested and Stored at Japanese Institutional Tissue Banks. Surgery Today, 41, 500-509. http://dx.doi.org/10.1007/s00595-010-4459-x

[3] Morimoto, K., Hoashi, T., Kagisaki, K., Yoshimatsu, J., Shiraishi, I., Ichikawa, H., Kobayashi, J., Nakatani, T., Yagihara, T., Kitamura, S. and Fujita, T. (2015) Impact of Ross Operation on Outcome in Young Female Adult Patients Wanting to Have Children. Circulation Journal. http://dx.doi.org/10.1253/circj.CJ-15-0410

[4] Ali, U., Copel, J. and Friedman, A. (2009) A Successful Pregnancy Outcome Following the Ross Procedure: A Case Report. American Journal of Perinatology, 26, 287-297. http://dx.doi.org/10.1055/s-0028-1103157

[5] Mastrobuoni, S., de Kerchove, L., Solari, S., Astarci, P., Poncelet, A., Noirhomme, P., Rubay, J. and El Khoury, G. (2015) The Ross Procedure in Young Adults: Over 20 Years of Experience in Our Institution. European Journal Cardio-Thoracic Surgery. http://dx.doi.org/10.1093/ejcts/ezv053

[6] Brown, J.W., Ruzmetov, M., Rodefeld, M.D., Mahomed, Y. and Turrentine, M.W. (2007) Incidence of and Risk Factors for Pulmonary Autograft Dilation after Ross Aortic Valve Replacement. Annals of Thoracic Surgery, 83, 17811789. http://dx.doi.org/10.1016/j.athoracsur.2006.12.066

[7] Ungerleider, R.M., Ootaki, Y., Shen, I. and Welke, K.F. (2010) Modified Ross Procedure to Prevent Autograft Dilatation. Annals of Thoracic Surgery, 90, 1035-1037. http://dx.doi.org/10.1016/j.athoracsur.2009.09.078 